\title{
Hard-To-Treat Idiopathic Refractory Autoimmune Haemolytic Anaemia with Reticulocytopenia
}

\author{
Marcelo Aveiro ${ }^{1}$, Gisela Ferreira ${ }^{2}$, Carla Matias ${ }^{1}$, Ana Oliveira $^{1}$, Tatiana Rodrigues ${ }^{1}$ \\ ${ }^{1}$ Internal Medicine Department, Centro Hospitalar do Baixo Vouga, Aveiro, Portugal \\ ${ }^{2}$ Haematology Department, Centro Hospitalar do Baixo Vouga, Aveiro, Portugal
}

Received: 03/11/2020

Accepted: $10 / 11 / 2020$

Published: 02/12/2020

How to cite this article: Aveiro M, Ferreira G, Matias C, Oliveira A, Rodrigues T. Hard-to-treat idiopathic refractory autoimmune haemolytic anaemia with reticulocytopenia. EJCRIM 2020;7: doi:10.12890/2020_002112.

Conflicts of Interests: The Authors declare that there are no competing interests.

This article is licensed under a Commons Attribution Non-Commercial 4.0 License

\section{ABSTRACT}

Autoimmune haemolytic anaemia (AIHA) is an uncommon condition characterized by increased destruction of erythrocytes associated with reticulocytosis in the great majority of cases. We present the case of a 68-year-old woman with jaundice and malaise. Investigation revealed AIHA with reticulocytopenia. The patient failed to respond to prednisolone or to rituximab. Azathioprine and epoetin beta were subsequently started, the prednisolone dose was increased, and the patient began to respond after 1 month. In AlHA, reticulocytopenia is a very rare presentation and a sign of great severity and poor outcome. The scarcity of therapeutic options in refractory cases poses a major challenge for physicians.

\section{LEARNING POINTS}

- Autoimmune haemolytic anaemia is a rare disorder characterized by decompensated acquired haemolysis caused by the host's immune system acting against its own red cell antigens.

- Concomitant presentation with reticulocytopenia is very rare and a sign of great severity and poor outcome.

- Treatment options in refractory cases still greatly rely on individual experience and expert opinion.

\section{KEYWORDS}

Haemolytic anaemia, reticulocytopenia, azathioprine

\section{INTRODUCTION}

Autoimmune haemolytic anaemia (AIHA) is a decompensated acquired haemolysis caused by the host's immune system acting against its own red cell antigens ${ }^{[1]}$. It is classified into primary/idiopathic and secondary types. Idiopathic AHAl is responsible for $50 \%$ of cases, and is diagnosed when no disease is clearly associated with the haemolysis. Secondary AHAI is associated with B-cell malignancies, autoimmune diseases, or drugs that can induce haemolysis ${ }^{[2]}$. The major determinants of clinical heterogeneity are the type of haemolysis (intravascular and/or extravascular) and erythroblastic response ${ }^{[3]}$.

$\mathrm{AHAl}$ is characterized by a normal/raised mean corpuscular volume (MCV), raised unconjugated bilirubin (uBrb) and lactate dehydrogenase (LDH), reduced haptoglobin, and peripheral blood smear (PBS) demonstrating polychromasia, spherocytes, erythrocyte fragmentation and/ or agglutination. The direct antiglobulin test (DAT) is the main serological assay used to diagnose AlHA ${ }^{[4]}$. The majority of AHAI cases are characterized by the presence of reticulocytosis, which is an index of red blood cell production. However, in some haemolytic conditions, the compensatory reticulocytosis may be inadequate or absent due to the presence of concomitant marrow infiltration, iron and vitamin 
deficiency, infection (e.g., parvovirus B19) or an autoimmune reaction against erythroid precursor cells ${ }^{[5]}$. In addition, reticulocytopenia can be observed in a minority of patients at presentation despite evidence of erythroid hyperplasia in the marrow ${ }^{[6]}$. Reticulocytopenic AHAI ( $\mathrm{rAHAl}$ ) may be a medical emergency due to an extremely high transfusion need with poor outcome ${ }^{[7,8]}$.

The first line of treatment is corticotherapy. Regarding second line treatment, there is still a lack of consensus regarding optimal management and the alternatives available rely on expert opinion and individual experience ${ }^{[9]}$.

\section{CASE DESCRIPTION}

We present the case of a 68-year-old female patient who was referred to the emergency department with a 10-day history of jaundice, malaise and choluria. She denied having started any new medications. Blood tests revealed haemoglobin (Hb) $4.2 \mathrm{~g} / \mathrm{dl}, \mathrm{MCV} 106 \mathrm{fl}$, reticulocytes 26×10\%/I (normal: 50-100×10\%/l), uBrb 4.02 mg/dl, LDH 610 U/I, undetectable haptoglobin and positive DAT (IgG 4+). PBS showed polychromasia but no evidence of microangiopathy. The patient was transfused with 2 units of red blood cells and was admitted to the internal medicine department.

During hospitalization, the patient maintained marked haemolysis and reticulocytopenia, requiring the transfusion of 18 units of red blood cells. An extensive aetiological study was carried out and excluded the presence of other conditions; serum ferritin and transferrin saturation, vitamin B12 and folic acid levels were normal. Thyroid function was also normal. Serological testing for Mycoplasma pneumoniae, human immunodeficiency virus, hepatitis B virus, hepatitis C virus, parvovirus B19, toxoplasmosis, Epstein-Barr virus, cytomegalovirus and VDRL was normal. Bone marrow aspiration and trephine biopsy did not reveal any major alterations. A complete autoimmune study was requested, but did not reveal positivity for any antibodies. Computed tomography of the skull, chest, abdomen and pelvis excluded neoplasia. A mammogram and breast ultrasound were also performed as well as positron emission tomography, none of which demonstrated any signs of malignancy. Thus, the diagnosis of idiopathic $\mathrm{rAHAl}$ was established.

Folic acid $5 \mathrm{mg}$ daily, proton-pump inhibitor and prednisolone $1 \mathrm{mg} / \mathrm{kg} / \mathrm{day}$ were started. After 22 days, the patient was still transfusiondependent and so was administered intravenous immunoglobulin (IVIG) $1 \mathrm{~g} / \mathrm{kg} / \mathrm{day}$ for 2 days and rituximab ( $375 \mathrm{mg} / \mathrm{m}^{2} / \mathrm{week}$ ) for $4 \mathrm{weeks}$ without any response. She then began azathioprine ( $1 \mathrm{mg} / \mathrm{kg} / \mathrm{day}$ ), with off-label epoetin beta (EPOb) 30,000 IU twice a week and the dose of prednisolone was increased to $2 \mathrm{mg} / \mathrm{kg} / \mathrm{day}$. On the 36th day of hospitalization and the 13 th day of prednisolone ( $2 \mathrm{mg} / \mathrm{kg} / \mathrm{day})$, azathioprine (50 mg daily) and EPOb, her Hb was $9.9 \mathrm{mg} / \mathrm{dl}$. Slow corticosteroid tapering was initiated and azathioprine was increased to $200 \mathrm{mg}$ daily, which she maintained at the time of discharge along with a reduction in prednisolone to $<1.5 \mathrm{mg} / \mathrm{kg} / \mathrm{day}$, EPOb, folic acid, calcium carbonate with calcitriol and prophylaxis against pneumocystosis.

The patient was later evaluated due to neutropenia, elevated liver enzymes and deep vein thrombosis, which led to discontinuation of azathioprine and EPOb and the initiation of a direct oral anticoagulant. The patient maintained $\mathrm{Hb}>12 \mathrm{~g} / \mathrm{dl}$ and prednisolone was tapered very slowly until it was discontinued 8 months after the initial symptoms.

\section{DISCUSSION}

The first-line treatment in primary AlHA is prednisolone $1 \mathrm{mg} / \mathrm{kg} /$ day. Nearly $80 \%$ of patients respond to corticosteroids, although the initial response may take several weeks. Second-line options include rituximab, azathioprine, ciclosporin, danazol, mycophenolate mofetil and splenectomy. There is no evidence to supports the use of one drug over another ${ }^{[1]}$. The temporal sequence of second-line options is still controversial, and no predictors of outcome are available ${ }^{[9]}$. In this patient, given the failed response to the treatments previously instituted, and the expected response rate of 60\%, it was decided to initiate azathioprine at the recommended dose of $100-200 \mathrm{mg} / \mathrm{day}{ }^{[10]}$. As previously mentioned, the presence of reticulocytopenia in AHAl indicates a poor prognosis and increased severity of disease and is sometimes considered a medical emergency. In such cases, the administration of EPOb should be considered as it increased reticulocyte counts and haemoglobin concentrations ${ }^{[11]}$.

We must always be alert to the potential adverse reaction of our treatment options. Common side effects of azathioprine include nausea, abdominal upset, bone marrow suppression, and rarely hepatotoxicity ${ }^{[12]}$. Azathioprine can cause bone marrow suppression that results in leukopenia in up to $27 \%$ of patients ${ }^{[13]}$. The overall incidence of azathioprine-induced hepatotoxicity is less than $1 \%$, and about $90 \%$ of cases reported occurred in males ${ }^{[12]}$. Erythropoietin-stimulating agents have been shown to increase rates of venous thromboembolic (VTE) events in cancer-associated patients ${ }^{[14]}$.

In conclusion, we presented a rare case of primary $\mathrm{rAHAl}$, which is frequently fatal. The patient was refractory to first and second-line treatments, only responding after several weeks on a maximum dose of prednisolone, azathioprine and off-label EPOb. Treatment options still rely greatly on individual experience and expert opinion. Given the lack of uniformity concerning AHAI treatment, more studies are required to strengthen therapeutic options. 


\section{REFERENCES}

1. Hill QA, Stamps R, Massey E, Grainger JD, Provan D, Hill A. The diagnosis and management of primary autoimmune haemolytic anaemia. Br J Haematol 2017;176(3):395-411.

2. Go RS, Winters JL, Kay NE. How I treat autoimmune hemolytic anemia. Blood 2017;129(22):2971-2979.

3. Petz LD, Garratty G. Immune hemolytic anemias. In: Petz LD, Garratty G, editors. Immune hemolytic anemias. 2nd ed. Philadelphia: Churchill Livingstone; 2004, p. iv.

4. Engelfriet CP, Overbeeke MA, von dem Borne AE. Autoimmune hemolytic anemia. Semin Hematol 1992;29(1):3-12.

5. Barcellini W, Fattizzo B. Clinical applications of hemolytic markers in the differential diagnosis and management of hemolytic anemia. Dis Markers 2015;2015:635670.

6. Liesveld JL, Rowe JM, Lichtman MA. Variability of the erythropoietic response in autoimmune hemolytic anemia: analysis of 109 cases. Blood 1987;69(3):820-826.

7. Conley CL, Lippman SM, Ness P. Autoimmune hemolytic anemia with reticulocytopenia: a medical emergency. JAMA 1980;244(15):1688-1690.

8. Fattizzo B, Zaninoni A, Nesa F, Sciumbata VM, Zanella A, Cortelezzi A, et al. Lessons from very severe, refractory, and fatal primary autoimmune hemolytic anemias. Am J Hematol 2015;90(8):E149-151.

9. Barcellini W, Fattizzo B, Zaninoni A, Radice T, Nichele I, Di Bona E, et al. Clinical heterogeneity and predictors of outcome in primary autoimmune hemolytic anemia: a GIMEMA study of 308 patients. Blood 2014;124(19):2930-2936.

10. Worlledge S, Brain M, Cooper A, Hobbs J, Dacie J. Immunosuppressive drugs in the treatment of autoimmune haemolytic anemia. Proc R Soc Med 1969;61:1312-1315.

11. Arbach O, Funck R, Seibt F, Salama A. Erythropoietin may improve anemia in patients with autoimmune hemolytic anemia associated with reticulocytopenia. Transfus Med Hemother 2012;39(3):221-223.

12. Horning K, Schmidt C. Azathioprine-induced rapid hepatotoxicity. J Pharm Technol 2014;30(1):18-20.

13. Huskisson EC. Azathioprine. Clin Rheum Dis 1984;10(2):325-332.

14. Bennett CL, Silver SM, Djulbegovic B, Samaras AT, Blau CA, Gleason KJ, et al. Venous thromboembolism and mortality associated with recombinant erythropoietin and darbepoetin administration for the treatment of cancer-associated anemia. JAMA 2008;299(8):914-924. 